\title{
OBJETOS DE APRENDIZAGEM NA PÓS-GRADUAÇÃO: UMA DISCUSSÃO A RESPEITO DE SIGNIFICADOS MATEMÁTICOS
}

\author{
Learning objects in a post-graduation course: a discussion about \\ mathematical meanings
}

\author{
Nilce Fátima Scheffer ${ }^{1}$
}

${ }^{1}$ Professora da Universidade Federal da Fronteira Sul - UFFS - Campus de Chapecó SC, Doutora em Educação Matemática, UNESP - Rio Claro SP, e-mail: nilce.scheffer@uffs.edu.br

Data do recebimento: 24/03/2020 - Data do aceite: 01/08/2020

RESUMO: Este trabalho objetiva apresentar pesquisa a respeito da utilização de Objetos de Aprendizagem desenvolvidos por professores em curso de Pós-Graduação. A construção desses objetos constituiu-se em possibilidade de agregar recursos interativos à prática docente da Educação Básica e Superior. $\mathrm{O}$ trabalho subsidiou professores para o acesso à construção de saberes interdisciplinares, no que tange ao uso de tecnologias digitais, a fim de auxiliar na produção de conhecimento. O estudo insere-se na perspectiva qualitativa. Os resultados apontam a relevância e a importância da construção e aplicação de objetos de aprendizagem na discussão de conceitos matemáticos, de dinâmicas concernentes ao ensino e aprendizagem, além de consequentes desdobramentos de propostas a futuras ações em sala de aula.

Palavras-chave: Objetos de Aprendizagem. Tecnologias Digitais. Formação de Professores. Conceitos Matemáticos.

\begin{abstract}
The aim of this study is to present a research conducted on the use of learning objects developed by teachers from a Post-graduation Course. The construction of these objects was an opportunity to add interactive features to the teaching practice of Basic and Higher Education. The work subsidized teachers on the access to interdisciplinary knowledge construction, regarding the use of digital technologies to support knowledge production. The study is based on qualitative perspective. The results point out the relevance and importance of the construction and application of learning objects in the
\end{abstract}


discussion of mathematical concepts, of dynamics concerning teaching and learning, in addition to the consequent development of proposals for future actions in the classroom.

Keywords: Learning Objects. Digital Technologies. Teacher Training. Mathematical Concepts.

\section{Introdução}

Diante da necessidade de refletir a respeito de subsídios inovadores para desenvolver saberes matemáticos com o uso de softwares e diferentes tecnologias na sala de aula de matemática, neste trabalho são apresentadas reflexões que se referem à definição, caracterização e classificação de objetos de aprendizagem, bem como sua construção, aplicação, análise e avaliação em um Curso de Formação de Professores em nível stricto sensu. Parte-se do pressuposto de que muitas são as indagações relativas à educação que influenciam o professor em formação continuada na busca de novas possibilidades de trabalho para o ensino da Matemática.

Tal discussão contempla novas competências para ensinar, amplamente discutidas e divulgadas na literatura, como indica Thurler (2002), pois a exploração das Tecnologias Digitais já faz parte do dia a dia da sala de aula nas escolas. Para Manrique e André (2006), num processo de formação as ações que serão desenvolvidas com professores são planejadas e, por sua vez, reagem às ações planejadas. Essas autoras estavam buscando compreender como se realizam as relações com o saber, no contexto de um processo de formação, aspecto que ocorreu de forma semelhante neste estudo.

O presente trabalho apresenta uma discussão e reflexão a respeito de novas alternativas à prática docente com a utilização de objetos de aprendizagem, destacando-se aí possibili- dades de criação ao professor. Por essa razão, "Qual é a Matemática presente nos objetos de aprendizagem construídos pelos alunos-professores de um grupo multidisciplinar?" é o problema desta investigação.

Inicialmente, efetua-se uma breve revisão quanto à definição, caracterização e classificação de objetos de aprendizagem e, em seguida, explicita-se a metodologia de pesquisa assumida na investigação, dados e análise. Para finalizar, apresenta-se um recorte dos dados obtidos a partir da construção dos objetos no grupo multidisciplinar, considerando as contribuições à Matemática dos objetos em foco, dando destaque para a organização dos dados em matriz de significados e para a análise, tendo em vista o problema da pesquisa e referencial.

\section{Objetos de Aprendizagem - em busca de definição}

Os objetos de aprendizagem representam iniciativas que se utilizam de diversas tecnologias para o ensino e aprendizagem na sala de aula nas diferentes disciplinas. São considerados recursos interativos, que, na última década, se voltaram para os processos metodológicos de ensino e aprendizagem. Com o advento da Educação a Distância, esses objetos foram avaliados como entidade, digital ou não digital, a ser usada e reutilizada ou referenciada como suporte tecnológico à ação escolar. 
Desse modo, um objeto de aprendizagem passou a ser considerado parte, ou melhor, peça discreta do conteúdo educacional, podendo ser um texto, um gráfico, uma animação, um arquivo de áudio, um vídeo, entre outros, sendo que cada um terá propósito educacional específico.

Para Hay e Knaack (2007), objetos de aprendizagem são ferramentas interativas, baseadas na web, que apoiam situações de aprendizagem de conceitos específicos que incrementam, ampliam ou orientam o processo cognitivo dos aprendizes.

Para uma atividade ser considerada objeto de aprendizagem, por exemplo, dentro de um módulo de estudo, desde sua concepção, precisa seguir, de acordo com Miranda (2009), determinados princípios e normas, para que possa ser replicada em outros contextos.

Segundo alguns autores, como González (2009), Sá e Machado (2003), Wiley (2002), Lütchemeyer (2012), os objetos de aprendizagem são recursos com funções e objetivos determinados, com recursos digitais ou não digitais, que podem ser combinados com outros objetos e reutilizados; tecnologias utilizadas de apoio às aulas, que podem ser orientadas à reflexão, interpretação e contextualização do conteúdo. Nesse sentido, os objetos de aprendizagem são tecnologias fundamentais de apoio às aulas que possibilitam desde mapas, gráficos e demonstrações, que podem ocorrer mediante vídeos ou simulações interativas.

Consequentemente, os objetos de aprendizagem são atividades que empregam diferentes mídias, recursos educacionais que podem se apresentar de diversas maneiras, contemplando livros, polígrafos, slides, roteiros de atividades ou animações digitais com auxílio de tecnologias, sempre com a possibilidade de reutilização, constituindo parte do cenário de investigações e relações vividas pelo professor.
Ao relacionar os objetos ao uso das TICs, autores como Sá e Machado (2003) destacam que esses são recursos on-line ou objetos que podem ser criados em qualquer mídia, como applet, animação em Flash, arquivos de vídeo ou áudio, foto, apresentação em PowerPoint ou website, e essa foi a proposta do estudo realizado com os alunos-professores em formação na Pós-Graduação.

Um objeto pode ser programado para utilizar materiais pedagógicos autoinstrutivos do laboratório de ensino, possuir elementos simples, desde um vídeo, ou música, ser visualizado de forma prática, a partir de uma apresentação no PowerPoint, ou até mesmo envolver programas mais elaborados que exigem um entendimento das linguagens de programação, o que poderá também dar suporte à educação a distância. Essas possibilidades com as TICs envolvem situações e instrumentos que estão ao alcance do professor no seu contexto, ambiente natural e de formação e atuação, tornando possível a visualização, aspecto que fortalece a aprendizagem e atribuição de significados matemáticos.

A visualização é considerada, por Borba e Villarreal (2005), como aspecto privilegiado do ambiente computacional, porém, segundo os autores é desprezada nos contextos de ensino de Matemática. Ao desprezar esses recursos da visualização em sala de aula, os professores esquecem que estão deixando de oferecer, para os estudantes, novas e mais dinâmicas possibilidades presentes na tela das tecnologias digitais para a construção de conhecimento.

Uma afirmação como essa conduz à necessidade de formação continuada do professor, o qual, segundo Bairral (2009), é um profissional que deve constantemente aprender a aprender e, principalmente, refletir criticamente sobre a sua prática. $\mathrm{O}$ estudo aqui apresentado é resultado de ações desenvolvidas em curso de formação continuada, 
apoiado por pesquisas e práticas de extensão, pesquisas de graduação e pós-graduação, considerando a utilização de tecnologias digitais no ensino da Matemática.

Desse modo, um objeto de aprendizagem é um recurso que pode ser utilizado para dar suporte à aprendizagem do aluno, um material eletrônico que contenha informações que possam contribuir, seja em forma de imagem, uma página HTML (da Internet), uma animação ou simulação.

Um exemplo disso é a Rede Interativa Virtual de Educação (RIVED), que, quando foi lançada como política educacional, teve por objetivo a produção de conteúdos pedagógicos digitais, na forma de objetos, que são atividades multimídia interativas. Os objetivos previstos nessa política de Educação a Distância abrangem: a produção de conteúdos pedagógicos digitais, na forma de objetos de aprendizagem; o estímulo do raciocínio e do pensamento crítico dos estudantes, associando o potencial da informática às novas abordagens pedagógicas; a melhora da aprendizagem nas disciplinas da educação básica e a formação cidadã do aluno; a promoção da produção e publicação na Internet dos conteúdos digitais para acesso gratuito; $\mathrm{e}$ a produção e utilização dos objetos de aprendizagem nas instituições de ensino superior e na rede pública de ensino.

Em 2004, a produção de objetos de aprendizagem ficou sob a responsabilidade de universidades brasileiras que estavam presentes em inúmeros estados, cuja ação recebeu o nome de Fábrica Virtual. Com a expansão da rede RIVED, previu-se também a produção de conteúdos nas diferentes áreas de conhecimento, para o ensino fundamental, profissionalizante e para atendimento às necessidades especiais.

Nesse sentido, os saberes que os professores produzem e executam nos objetos de aprendizagem passaram a assumir seu valor por estarem relacionados com as suas próprias histórias, vivências e culturas nas quais estavam inseridos. Para Souza Junior e Lopes (2007), quando se concebe o professor como profissional reflexivo e investigador de sua prática, passa-se a enfrentar o problema do distanciamento e estranhamento entre os saberes científicos, praticados/produzidos pela academia, e aqueles praticados/produzidos pelos professores na prática docente com reflexão. Por essa razão, entende-se que o trabalho coletivo poderia promover o desenvolvimento profissional tanto dos professores como dos formadores de professores, pois nesse momento percebem-se múltiplos saberes acontecendo. Esse desenvolvimento profissional, segundo Tardif (2007), ocorre em formações que, com base nos saberes e produção de saberes, constituem, consequentemente, dois polos complementares e inseparáveis.

Outro aspecto relacionado aos objetos de aprendizagem, já destacado por Nunes (2004) quando se referia ao professor que tem à sua disposição objetos de diferentes tipos, diz que ele pode planejar suas aulas com o uso de tais objetos, conseguindo maior flexibilidade para se adaptar ao ritmo e ao interesse dos alunos, tendo em vista seus objetivos de ensino.

Vale considerar que a utilização desses objetos poderá ressignificar a prática pedagógica, pois assim o processo de ensino e aprendizagem beneficia-se de várias linguagens para motivar ou contextualizar um tema, por exemplo, a visualização de conceitos geométricos. Diante disso, o uso desses objetos em sala de aula pode ser um facilitador, pois o professor pode utilizar aquele que melhor atender aos seus objetivos.

Esse aspecto é confirmado por Gallotta e Nunes (2004), quando afirmam que os objetos de aprendizagem permitem a construção de contextos digitais para os conceitos que serão explorados, usando ferramentas mi- 
diáticas, tais como música, desenhos, gráficos, simulações e jogos. Enfim, permitem a contextualização no sentido de estabelecer relações entre conteúdos, suas aplicações práticas e a inter-relação com várias disciplinas.

No que diz respeito à construção em Matemática, principalmente quando se trata da análise, associação, construção geométrica, resolução de problemas e busca de diferentes soluções, esses objetos têm contribuído, significativamente, com a dinâmica e a motivação que despertam para a aprendizagem em interação com as tecnologias digitais.

Bettio e Martins (2004) destacam características dos objetos que promovem a aprendizagem, tais como Flexibilidade, Facilidade para atualização, Customização, Interoperabilidade, Aumento do valor de um conhecimento, além da Indexação e Procura em qualquer banco que esteja disponível para consultas.

Essas características dos objetos tornam possível uma melhor compreensão das mudanças por que passou o processo de formação de professores com o advento das tecnologias. De maneira geral, Tardif e Raymond (2000) afirmam que, ao fazer uso de múltiplos saberes, "a noção de saber" assume sentido amplo, englobando os conhecimentos, as competências, as habilidades e as atitudes docentes. Desse modo, aquilo que foi chamado, muitas vezes, de saber, de saber-fazer e de saber-ser passa a influenciar a prática docente de forma incisiva, contribuindo para a aprendizagem.

Outro aspecto a considerar nessa relação, apontado por González (2005), é a classificação em objetos de prática, de avaliação, de colaboração e de instrução no uso pedagógico: os primeiros constituem-se em atividades instrucionais e orientadas para a autoaprendizagem, principalmente por meio de simulações de ações reais; os objetos de avaliação têm por finalidade identificar o nível de conhecimento de um aprendiz, sendo utilizados para verificar os conhecimentos prévios ao processo de aprendizagem; os objetos de colaboração são utilizados para a comunicação em ambientes de aprendizagem colaborativa, sendo aqueles que envolvem compartilhamento de experiências e conhecimentos, por meio de mensagens síncronas ou assíncronas; e os objetos de instrução relacionam-se às atividades destinadas ao apoio da aprendizagem.

Nesse sentido, de acordo com Lütchemeyer e Scheffer (2011), e Lütchemeyer (2012), os objetos de instrução são aqueles que combinam textos, imagens, filmes, animação, vídeos, perguntas e exercícios. Com a finalidade de proporcionar uma aprendizagem interativa, este estudo voltase principalmente para esse tipo de objeto.

No estudo aqui apresentado, constatou-se que a construção de um objeto de aprendizagem para trabalhar um tema específico pode constituir-se em proposta alternativa capaz de contemplar novas maneiras de ensinar conceitos matemáticos, aspectos apontados por Sant'ana, Amaral e Borba (2012) como fundamentais para professores em processo de formação e que, consequentemente, representarão uma boa contribuição ao ensino, tendo em vista mudanças na prática pedagógica.

Nos dias atuais, os ambientes informatizados podem ser mais explorados e utilizados no ensino, de modo que o acesso, ou as condições exploratórias desses recursos na prática do professor, sejam eficazes e decisivos. Nesse sentido, Assis e Bezerra (2011) apontam que a utilização de software em sala de aula deve ser norteada por interesses pedagógicos, pois o mesmo não implica nenhuma mudança no processo educacional, considerando que, as tecnologias digitais nos dias atuais, já fazem parte da vida das pessoas. Por outro lado, autores - como Gravina e Basso (2012) - apontam que a variedade de recursos que temos à nossa disposição permite um avanço 
na discussão que trata de inserir a escola na cultura virtual.

Concepções dessa natureza traduzem a necessidade de reflexões, estudos e pesquisas visando a redimensionar a educação atual, com o resgate dos saberes tecnológicos para a sala de aula, nos quais as ideias e os conceitos fazem sentido. Segundo Scheffer (2017), estes favorecem, principalmente, a análise dos procedimentos de resolução, conceitos e estratégias desenvolvidas pelos estudantes, sendo cada vez mais útil como recurso educativo para possibilitar a construção do conhecimento.

Esta pesquisa foi realizada com alunos-professores de cursos de Pós-Graduação, com o intuito de buscarem e refletirem novos caminhos à prática pedagógica, pois, de acordo com Scheffer e Heineck (2016, p. 18), as tecnologias digitais, "presentes no cotidiano das pessoas, representam a necessidade de serem utilizadas na sala de aula, considerando que podem contribuir para que o processo de ensino e de aprendizagem se torne mais atraente, crítico, dinâmico e significativo".

Consequentemente, no caso do objeto de aprendizagem, Scheffer et al. (2018) destacam que o mesmo pode ser programado e planejado pelo professor no sentido de envolver e utilizar materiais pedagógicos do laboratório de ensino integrado às tecnologias digitais com elementos simples, como um vídeo ou uma música. Pode também ser visualizado de forma prática a partir de uma apresentação no PowerPoint ou, de programas mais elaborados que exijam entendimento de linguagens de programação, tendo em vista possibilidades com tecnologias digitais que estão ao alcance do professor no contexto escolar.

Por esse motivo, destaca-se a perspectiva de que os professores formadores das universidades, que trabalham com investigação relacionada à formação inicial e continuada de docentes em parceria com a Educação Básica e redes de ensino, têm o firme propósito de desenvolver projetos destinados ao trabalho com objetos virtuais de aprendizagem no contexto escolar.

\section{Contexto e aspectos metodológicos da pesquisa}

Considerando que o aprender e o ensinar estão relacionados e associados à prática e às escolhas metodológicas dos professores, neste trabalho de pesquisa qualitativa com tratamento empírico dos dados buscou-se, inicialmente, explorar com os alunos-professores a definição, caracterização e classificação dos objetos de aprendizagem, a sua construção, os objetivos e conceitos a serem explorados, a área de abrangência, a série, a duração, os recursos fundamentais e o próprio desenvolvimento da prática em sala de aula.

Superada essa fase, passou-se à prática de construção dos objetos no Laboratório de Informática, que envolveu desde a busca detalhada de sites, imagens, filmes, músicas e textos relacionados aos temas escolhidos para estudo, momento em que cada aluno-professor dedicou seu tempo em laboratório para a investigação, testagem e estabelecimento de links necessários.

Os dados foram coletados a partir da análise dos objetos, considerando sua abordagem prática, o que possibilita, de acordo com Powell (2015), ver e rever as atividades propostas em cada objeto, tendo em vista o tema e os objetivos previstos para os mesmos, o que potencializa o respectivo processo de interpretação a qualquer momento. Dentre as alternativas consideradas na coleta de dados, estão as anotações em caderno de campo, observações, registros e descrição de representações construídas nos objetos. Os dados e registros foram organizados em matrizes de 
significados, conforme a Quadro I.

$\mathrm{Na}$ análise de dados, consideraram-se os significados matemáticos associados e atribuídos a cada objeto com o olhar voltado para o planejamento, a organização, a estruturação, a abrangência e as ferramentas didáticas utilizadas na construção deles pelos alunos-professores, além dos conceitos matemáticos presentes nos objetos que contemplaram áreas do conhecimento como Matemática, Ciências, Contabilidade, Microbiologia e Física.

\section{Dados em discussão e análise: um breve recorte}

Apresenta-se, a seguir, um breve recorte dos dados do estudo, que de acordo com Severino (2012), a interpretação teórica de dados empíricos destaca o entrelaçamento entre o lógico e o real, promovendo assim a significação. Desse modo, o estudo empírico contemplou a análise de dez objetos de aprendizagem construídos para diferentes níveis de ensino, que vão desde a Educação Básica à Superior, em diferentes áreas, conforme o perfil diversificado do grupo de alunos-professores, participantes de um Curso de Pós-Graduação voltado para o Ensino Científico e Tecnológico.

Por um lado, o objetivo do estudo era desenvolver propostas pedagógicas inovadoras favoráveis à aprendizagem em sala de aula e, por outro, refletir sobre o argumento de que o material pedagógico digital pode ser planejado, elaborado e construído pelo próprio professor de acordo com a sua realidade e contexto escolar.

O recorte analítico aqui apresentado voltou-se para a presença de significados matemáticos associados aos diferentes temas dos objetos, conforme se destaca na matriz de significados explicitada na Quadro I, de dados do estudo empírico.
A partir dessa matriz de significados (Quadro I), pode-se observar que os objetos envolvidos neste estudo se voltaram para os diferentes níveis de ensino e áreas de acordo com a atuação dos alunos-professores. Os objetos todos foram elaborados para dar conta de processos de ensino e aprendizagem, contemplando aspectos matemáticos, científicos, lúdicos e aplicações a partir da resolução de problemas, aspectos que podem ser confirmados por estudos de Sá Filho e Machado (2003), Scheffer; Bittarello e Rovani, (2010), Scheffer (2017) e Scheffer et al. (2018).

Os objetos destacados neste estudo podem ser classificados como Objetos de Instrução, porque, conforme González (2005), se relacionam a atividades destinadas ao apoio do ensino e da aprendizagem, combinando textos imagens, filmes, músicas, animação, vídeos, PowerPoint, perguntas e atividades interativas.

Os significados matemáticos que se apresentam nos diferentes objetos evidenciam aspectos tais como: componentes do estudo de geometria, resolução de problemas, taxas, percentagem, tabelas, gráficos e medidas que se destacaram com maior frequência.

O estudo possibilitou uma reflexão sobre a prática profissional do professor, a docência, o verdadeiro sentido que a noção de saber assume na vida do docente, como destacado pelos autores Gravina e Basso (2012), considerando a variedade de recursos que temos à nossa disposição, que permitem uma discussão voltada à inserção da escola na cultura do virtual. Para finalizar este estudo vale considerar outros aspectos, tais como a atitude docente de perspicácia quanto à presença da matemática nos diferentes objetos analisados e a validade da realização de intervenções no trabalho escolar, uma vez que o seu papel foi de planejar, elaborar e construir objetos interativos, tendo em vista o próprio contexto da prática educativa. 
Quadro I - Matriz de Significados dos Objetos de Aprendizagem

\begin{tabular}{|c|c|c|c|c|}
\hline Temas & Animação & Programas & Nível & $\begin{array}{l}\text { Significados matemáticos } \\
\text { associados ao Tema }\end{array}$ \\
\hline Jogo de Xadrez & $\begin{array}{c}\text { Desenho animado } \\
\text { Filmes }\end{array}$ & $\begin{array}{c}\text { PowerPoint } \\
\text { Programa de } \\
\text { Xadrez virtual }\end{array}$ & $\begin{array}{l}\text { Ensino } \\
\text { Fundamental }\end{array}$ & $\begin{array}{c}\text { Diagonais, } \\
\text { lateralidade, } \\
\text { paralelas, } \\
\text { perpendiculares e } \\
\text { história da matemática. }\end{array}$ \\
\hline O Tempo & Filmes, textos & PowerPoint & $\begin{array}{l}\text { Ensino } \\
\text { Fundamental }\end{array}$ & $\begin{array}{c}\text { Medidas de tempo, } \\
\text { utilização do relógio, } \\
\text { graus e história da matemática. }\end{array}$ \\
\hline $\begin{array}{l}\text { Geometria dos } \\
\text { Mosaicos }\end{array}$ & $\begin{array}{c}\text { Filmes, textos e } \\
\text { Fotos }\end{array}$ & PowerPoint & $\begin{array}{l}\text { Ensino } \\
\text { Fundamental }\end{array}$ & $\begin{array}{l}\text { Ângulos, simetria, polígonos } \\
\text { regulares e irregulares, lados, } \\
\text { vértices e diagonais, círculos } \\
\text { concêntricos,cilindro e esfera } \\
\text { e história da matemática. }\end{array}$ \\
\hline $\begin{array}{l}\text { Contabilidade } \\
\text {-Controle de } \\
\text { Estoque }\end{array}$ & Filmes & $\begin{array}{c}\text { PowerPoint } \\
\text { Planilha Excel }\end{array}$ & Ensino Médio & $\begin{array}{l}\text { Matemática comercial, } \\
\text { resolução de problemas, } \\
\text { relação entre taxas e } \\
\text { percentagem. }\end{array}$ \\
\hline Logaritmos & $\begin{array}{c}\text { Filmes, textos e } \\
\text { músicas }\end{array}$ & $\begin{array}{l}\text { PowerPoint } \\
\text { Hot Potatoes }\end{array}$ & Ensino Médio & $\begin{array}{l}\text { Logaritmos, conceituação } \\
\text { e suas propriedades, } \\
\text { potenciação, } \\
\text { resolução de problemas, } \\
\text { história da matemática, } \\
\text { logaritmos e música. }\end{array}$ \\
\hline Ciclo da Vida & $\begin{array}{l}\text { Filmes, textos e } \\
\text { músicas }\end{array}$ & PowerPoint & Ensino Médio & $\begin{array}{l}\text { Taxas, percentagem, medidas, } \\
\text { estatística, tabelas e gráficos. }\end{array}$ \\
\hline Alimentação & $\begin{array}{c}\text { Filme, textos e } \\
\text { figuras } \\
\text { Desenho animado }\end{array}$ & PowerPoint & $\begin{array}{c}\text { Ensino } \\
\text { Fundamental e } \\
\text { Médio }\end{array}$ & $\begin{array}{l}\text { Taxas, contagem, percenta- } \\
\text { gem, medidas, quantidades } \\
\text { contínuas e gráficos e tabelas. } \\
\text { Horários, análise de rótulos, } \\
\text { taxas de calorias, gorduras, } \\
\text { vitaminas e minerais. }\end{array}$ \\
\hline Saúde Cutânea & $\begin{array}{l}\text { Filmes, fotos, } \\
\text { textos e músicas }\end{array}$ & PowerPoint & Ensino Médio & $\begin{array}{l}\text { Taxas, percentagem e gráfi- } \\
\text { cos e matrizes. }\end{array}$ \\
\hline Microbiologia & $\begin{array}{l}\text { Filmes, fotos, } \\
\text { textos e músicas }\end{array}$ & PowerPoint & Ensino Superior & $\begin{array}{l}\text { Taxas, percentagem, tabelas e } \\
\text { gráficos e estudo de matrizes. }\end{array}$ \\
\hline Marketing & Filmes & $\begin{array}{c}\text { PowerPoint } \\
\text { Planilha Excel }\end{array}$ & Ensino Superior & $\begin{array}{c}\text { Tabelas e gráficos, estudo de } \\
\text { matrizes. }\end{array}$ \\
\hline
\end{tabular}

Fonte: Arquivos da pesquisa. 


\section{Considerações Finais}

Os objetos de aprendizagem, nos dias atuais, representam uma contribuição fundamental para o ensino, tendo em vista a prática pedagógica, que se volta ao investimento em recursos digitais, acesso e consulta, sempre que houver necessidade e interesse em um trabalho mais investigativo.

Diante disso, os objetos com animação e possibilidades de simulação interativa auxiliam na compreensão e construção de significados. Os estudantes têm a oportunidade da visualização, de forma dinâmica e animada, de modo a testar e construir seus significados de maneira autônoma e interativa. Outro aspecto válido é que os objetos proporcionam a observação detalhada de certos fenômenos, reações ou acontecimentos a partir de simulações. Nessa perspectiva, os objetos oferecem maior facilidade à compreensão de fenômenos e conceitos relativos aos temas abordados, além de permitirem sua reutilização pela própria disciplina ou por outras.

Contudo, os objetos se tornam fundamentais, uma vez que, para interagir com eles, o educando vai construindo o entendimento do conteúdo. Por isso, os referidos objetos são entendidos como instrumentos de apoio pedagógico, tendo em vista o conteúdo trabalhado, auxiliando na revisão dos mesmos, além de proporcionar o desafio de uma construção de maneira agradável e interativa.

Esse tipo de recurso possibilita também testar diferentes caminhos, acompanhar a evolução temporal de relações de causa e de efeito, de visualizar construções de diferentes pontos de vista, de comprovar hipóteses a partir das animações e simulações. Tais instrumentos tornam-se poderosos para despertar novas opiniões, relacionar conceitos, despertar a curiosidade e resolver problemas.

Assim as atividades interativas oferecem inúmeras oportunidades de exploração de fenômenos e de conceitos muitas vezes inviáveis ou inexistentes em outras abordagens. Enfatizam-se, então, os aspectos apontados como facilitadores da caminhada do professor com seus educandos e que os mesmos oferecem inúmeras possibilidades à ação escolar.

Para concluir, pode-se dizer que os temas propostos neste estudo e desenvolvidos na forma de objetos de ensino, ofereceram aos alunos-professores uma visão diferente para o levantamento dos conceitos matemáticos relacionando-os com os temas construídos e tecnologias digitais. 


\section{REFERÊNCIAS}

ASSIS, C. C.; BEZERRA, M. C. A. Formação Continuada de professores de Matemática: integrando softwares educativos à prática docente. In: COMITÊ INTERAMERICANO DE EDUCAÇÃO MATEMÁTICA - CIAEM-IACME, 13, 2011. Anais [...] Recife PE, 2011.

BAIRRAL, M. A. Tecnologias da Informação e Comunicação na Formação e Educação Matemática. Rio de Janeiro: UFRRJ, 2009.

BETTIO, R. W.; MARTINS, A. Objetos de Aprendizado: Um novo modelo direcionado ao Ensino a Distância. Disponível em: http://www.noticias.universia.com.br. Publicado em 17/12/2004. Acesso em: 10 abr. 2010.

BORBA, M. C.; VILLAREAL M.E. Humans-with-Media and the Reorganization of Mathematical Thinking: Information and Communication Technologies, Modeling, Experimentation and Visualization. New York: Springer, 2005.

GRAVINA, M. A.; BASSO, M. V. A. Mídias digitais na educação matemática. In: GRAVINA, M. A. (Org.) et al. Matemática, Mídias Digitais e Didática: tripé para a formação do professor de Matemática. Porto Alegre: Evangraf, 2012. Cap. 1, p. 4.

GALLOTTA, A.; NUNES, C. A. Objetos de aprendizagem a serviço do professor, 2004.

Disponível em: Acesso em: 12 out. 2012.

GONZÁLEZ, L. A. G. Um Modelo Conceitual para Aprendizagem Colaborativa Baseada na Execução de Projetos pela Web. 2005. 254f. Tese (Doutorado) - Escola Politécnica da Universidade de São Paulo, Universidade de São Paulo, São Paulo, SP. 2005.

GONZÁLEZ, L. A. G.; RUGGIERO, W. V. Collaborative e-learning and Learning Objects. IEEE Latin America Transactions, v. 7, n 5, p. 569-577, set 2009.

HAY, R. H.; KNAACK, L. Evaluating the learning in learning objects. Open Learning: The Journal of Open and Distance Education, v. 22, n. 1, p. 5-28, 2007.

LÜTCHEMEYER, R. R. Investigar a conceituação de logaritmos e sua aplicação a partir da utilização de um Objeto de Aprendizagem, 2012. 112f. Dissertação (Mestrado em Ensino Científico e Tecnológico) - Universidade Regional Integrada do Alto Uruguai e das Missões Câmpus de Santo Ângelo, Santo Ângelo, RS. 2012.

LÜTCHEMEYER, R. R.; SCHEFFER, N. F. Objetos de aprendizagem na construção do conceito de logaritmos. In: Ensino de Ciências e Tecnologia em Revista. Santo Ângelo, RS. v. 1, n. 2, p. 1-6, jul./dez. 2011.

MANRIQUE, A.L. E ANDRÉ, M. E. D. Relações com saberes na formação de professores In: NACARATO, A. M., PAIVA, M. A. V. (Org.), A formação do professor que ensina matemática: perspectivas e pesquisas, Belo Horizonte: Autêntica, 2006. p. 133-148

MIRANDA, G. M. Concepção de Conteúdos e Curso Online, In: MIRANDA, G. M. Ensino online e aprendizagem multimédia. Lisboa: Relógio D`Água, 2009. p. 81-110.

NUNES, C.; Objetos de aprendizagem a serviço do professor. 2004. Disponível em http://www. microsoft.com/brasil/educação/parceiro/objeto. Acesso em: 05 out. 2010.

POWELL, A. B. Métodos de pesquisa em Educação Matemática: usando a escrita, o vídeo e Internet. Campinas, SP: Mercado de Letras, 2015. 
SÁ FILHO, C. S.; MACHADO, E. C. O Computador como Agente Transformador da Educação e o Papel do Objeto de Aprendizagem. 2003. Disponível em http://www.abed.org.br/seminario/ texto11.doc/. Acesso em: 14 jan. 2010.

SANT'ANA, R. C.; AMARAL, R. B.; BORBA, M. C. O uso de softwares na prática profissional do professor de Matemática. Ciência \& Educação, v. 18, n. 3, p. 527-542, 2012.

SCHEFFER, N.; BITTARELLO, M. L.; ROVANI, S. O Teorema de Pitágoras, uma demonstração dinâmica com o software Wingeom. Revista Vivências, v. 6 n. 10, p.1 - 6. 2010

SCHEFFER, N.; HEINECK, A. E. Ambientes Informatizados de Aprendizagem na investigação de construções geométricas: uma experiência com professores do Oeste Catarinense. Caminho Aberto - Revista de Extensão do IFSC, n. 4, p. 16-22, jul. 2016.

SCHEFFER, N. Tecnologias digitais e representação matemática de movimentos corporais. Curitiba: Appris, 2017.

SCHEFFER, N. et al. Uma interação com objetos virtuais de aprendizagem na discussão de conceitos geométricos. In: SCHEFFER, N.; COMACHIO, E.; CENCI, D. (Org.). Tecnologias da Informação e Comunicação na Educação Matemática: articulação entre pesquisas, objetos de aprendizagem e representações. Curitiba: CRV, 2018, p. 31-61.

SEVERINO, A. J. Pós-graduação e pesquisa: o processo de produção e de sistematização do conhecimento no campo educacional. In: BIANCHETTI, L.; MACHADO, A. M. N., A Bússola do Escrever. São Paulo: Cortez Editora, 3. ed., 2012 p. 82-101.

OUZA JUNIOR, A. J.; LOPES, C. R. Saberes docentes e o desenvolvimento de objetos de aprendizagem. In: PRATA, C. L. E.; NASCIMENTO, A. C. A. A. Objetos de aprendizagem: uma proposta de recurso pedagógico. Brasília: MEC, SEED, 2007. p.7-16.

TARDIF, M. Saberes docentes e formação profissional. 8. ed. Petrópolis: Vozes, 2007.

TARDIF, M.; RAYMOND, D. Saberes, tempo e a aprendizagem do trabalho do Magistério.

Educação e Sociedade: revista quadrimestral de Ciência da Educação. Campinas SP, n. 73, p. 209244, 2000. CEDES.

THURLER. M. G. Da Avaliação dos Professores à Avaliação dos Estabelecimentos Escolares. In: PERRENOUD, P.; THURLER, M. G., As Competências para Ensinar no século XXI: A Formação dos professores e o desafio da avaliação. Porto Alegre, RS: Artmed Editora, 2002.

WILLEY, D. A. Connecting learning objects to instructional design theory: A definition, a metaphor, and a taxionomy (2002). Disponível em: http://reusability.org/read/ chapters/wiley.doc/ Acesso em: 10 fev. 2010. 
